\title{
Embryonic environment and transgenerational effects in quail
}

\author{
Sophie Leroux', David Gourichon², Christine Leterrier ${ }^{3,4,5,6}$, Yann Labrune ${ }^{1}$, Vincent Coustham \\ Sandrine Rivière ${ }^{2}$, Tatiana Zerjal ${ }^{8}$, Jean-Luc Coville ${ }^{8}$, Mireille Morisson ${ }^{1}$, Francis Minvielle ${ }^{8}$ \\ and Frédérique Pitel ${ }^{1 *}$ (D)
}

\begin{abstract}
Background: Environmental exposures, for instance to chemicals, are known to impact plant and animal phenotypes on the long term, sometimes across several generations. Such transgenerational phenotypes were shown to be promoted by epigenetic alterations such as DNA methylation, an epigenetic mark involved in the regulation of gene expression. However, it is yet unknown whether transgenerational epigenetic inheritance of altered phenotypes exists in birds. The purpose of this study was to develop an avian model to investigate whether changes to the embryonic environment had a transgenerational effect that could alter the phenotypes of third-generation offspring. Given its impact on the mammalian epigenome and the reproductive system in birds, genistein was used as an environment stressor.

Results: We compared several third-generation phenotypes of two quail "epilines", which were obtained from genistein-injected eggs (Epi+) or from untreated eggs (Epi-) from the same founders. A "mirrored" crossing strategy was used to minimize between-line genetic variability by maintaining similar ancestor contributions across generations in each line. Three generations after genistein treatment, a significant difference in the sexual maturity of the females, which, after three generations, could not be attributed to direct maternal effects, was observed between the lines, with Epi+ females starting to lay eggs later. Adult body weight was significantly affected by genistein treatment applied in a previous generation, and a significant interaction between line and sex was observed for body weight at 3 weeks. Behavioral traits, such as evaluating the birds' reaction to social isolation, were also significantly affected by genistein treatment. Yet, global methylation analyses revealed no significant difference between the epilines.

Conclusions: These findings demonstrate that embryonic environment affects the phenotype of offspring three generations later in quail. While one cannot rule out the existence of some initial genetic variability between the lines, the mirrored animal design should have minimized its effects, and thus, the observed differences in animals of the third generation may be attributed, at least partly, to transgenerational epigenetic phenomena.
\end{abstract}

\section{Background}

Epigenetic phenomena, such as DNA methylation, histone modifications, changes in chromatin structure or effects of non coding RNAs, affect gene expression and thus are expected to have important effects on phenotypes. The phenotypic diversity of a population is the result of both genetic and epigenetic variations, with

\footnotetext{
*Correspondence: frederique.pitel@inra.fr

${ }^{1}$ GenPhySE, Université de Toulouse, INRA, INPT, ENVT, 31326 Castanet Tolosan, France

Full list of author information is available at the end of the article
}

epigenetics accounting for a portion of the variability of complex traits that is linked to interactions with the environment $[1,2]$. The real contribution of epigenetics to phenotypic variation remains to be evaluated, but it is an attractive new path in animal breeding that might help to explain the missing causality of complex traits [3]. In recent years, a growing number of studies have shown that epigenetic information can be transmitted across generations. In particular, the intergenerational transmission of DNA methylation and the influence of epigenetic marks on phenotype variability has been 
clearly established in plants [4]. These phenomena could also partly explain the "missing heritability" described in genome-wide association studies (GWAS) in humans $[5,6]$. The parental environment has been demonstrated to influence the phenotype of direct offspring in several mammalian species $[7,8]$, but a debate remains as to the actual existence of transgenerational inheritance of epigenetic marks that are acquired following particular environmental exposures. In mammals, a change in the environment of a pregnant F0 mother may have a direct influence on her developing F1 progeny and on the primordial germ cells carried by the $\mathrm{F} 1$ embryo that will give rise to the F2 generation. Therefore, "true" transgenerational epigenetic transmission is only observable in the F3 generation and beyond $[9,10]$. Non-genetic transgenerational inheritance has been clearly demonstrated in several organisms, such as Caenorhabditis elegans, and involves histone marks and small RNAs as well as other unknown mechanisms [11-14]. In vertebrates, several studies have used rodent models and have assessed the effect of vinclozolin on the health of generations F1 to F4. These studies have shown that the influence of vinclozolin on fertility or organic diseases seemed to be transmitted to subsequent generations through the male germline [15-18]. The transgenerational effects of environmental contaminant exposures during embryonic development have also been recently demonstrated in medaka [19]. The existence of a germline-dependent epigenetic effect, through histone modification, DNA methylation or small RNAs, has thus been identified in various species including worms and mammals (see [20-22]), but to the best of our knowledge there are no reports about transgenerational epigenetic inheritance in birds. The objective of our study was to test for the existence of epigenetic transmission in third-generation birds. We chose to use the Japanese quail as a model species because of its short generation interval, small size and well-established husbandry procedures, and because it is closely related to chicken [23]. Two lines of quail were produced from fertilized eggs from the same founder population. The phytoestrogen genistein, a putative methylation modifier (see [24]), was injected into the eggs of the Epi+ line, whereas the eggs of the Epi- line remained untreated. After three generations of parallel within-line breeding, without further injection, several traits were measured and compared between the two lines, in order to estimate to what extent transgenerational epigenetic transmission accounted for differences between the two quail lines.

\section{Methods}

\section{Animals and experimental design}

Animals were bred at INRA, UE1295 Pôle d'Expérimentation Avicole de Tours, F-37380 Nouzilly in accordance with European Union Guidelines for animal care, following the Council Directives 98/58/EC and 86/609/EEC. Animals were maintained under standard breeding conditions and were subjected to minimal disturbance. The farm is registered with the French Ministry of Agriculture under license number C37-175-1 for animal experimentation. The experiment was conducted under authorization 37-002.

Founders were chosen from the HSR (high social reinstatement) quail line that was developed by divergent selection on social motivation [25]. Two new lines were produced from 10 founding pairs: fertilized eggs from each pair were divided into two groups, a control group and a group treated by injection of genistein (Sigma-Aldrich) before incubation. The concentration of genistein used $(500 \mu \mathrm{g}$ per egg, in $50 \mu \mathrm{L}$ of sesame oil, Sigma-Aldrich) was determined according to the indications from a study using genistein injections in quail eggs [26]. The control group was not injected because the objective of our study was to observe the putative transgenerational transmission of methylation changes, regardless of the cause of the methylation profile differences between treated and non-treated controls. Indeed, global DNA methylation levels may be affected when control individuals are exposed only to the solvent used to dilute the product, as is the case in mosquitos [27]. However, no differences in global methylation are usually detected between non-injected and oil vehicle-injected controls [28].

The individuals hatched from these eggs (two or three birds per treatment group and pair of founders) constituted the G0 generation of the "Epi-" (control), and "Epi+" (genistein-treated eggs) lines (Fig. 1). Two generations were then produced for each line with exact parallel pedigrees, by mirrored single-pair matings at each generation (see Additional file 1: Figure S1), so that the expected genetic contribution of each founder was identical. This minimized the initial genetic differences between the two lines and maximized the likelihood that any observed third-generation line differences was due to the transmission of non-genetic information, beyond expected Mendelian sampling. For each line, the third-generation individuals were produced in sufficient numbers for the comparison of individual production traits. On average, 128 quails per sex and per line were produced under standard rearing conditions. The rearing environment was the same for all animals of each generation.

\section{Analysis of the performance of the third-generation individuals}

The traits measured are listed in Table 1 . The body weight of all individuals $(\mathrm{n}=513)$ was measured at 3 weeks of 


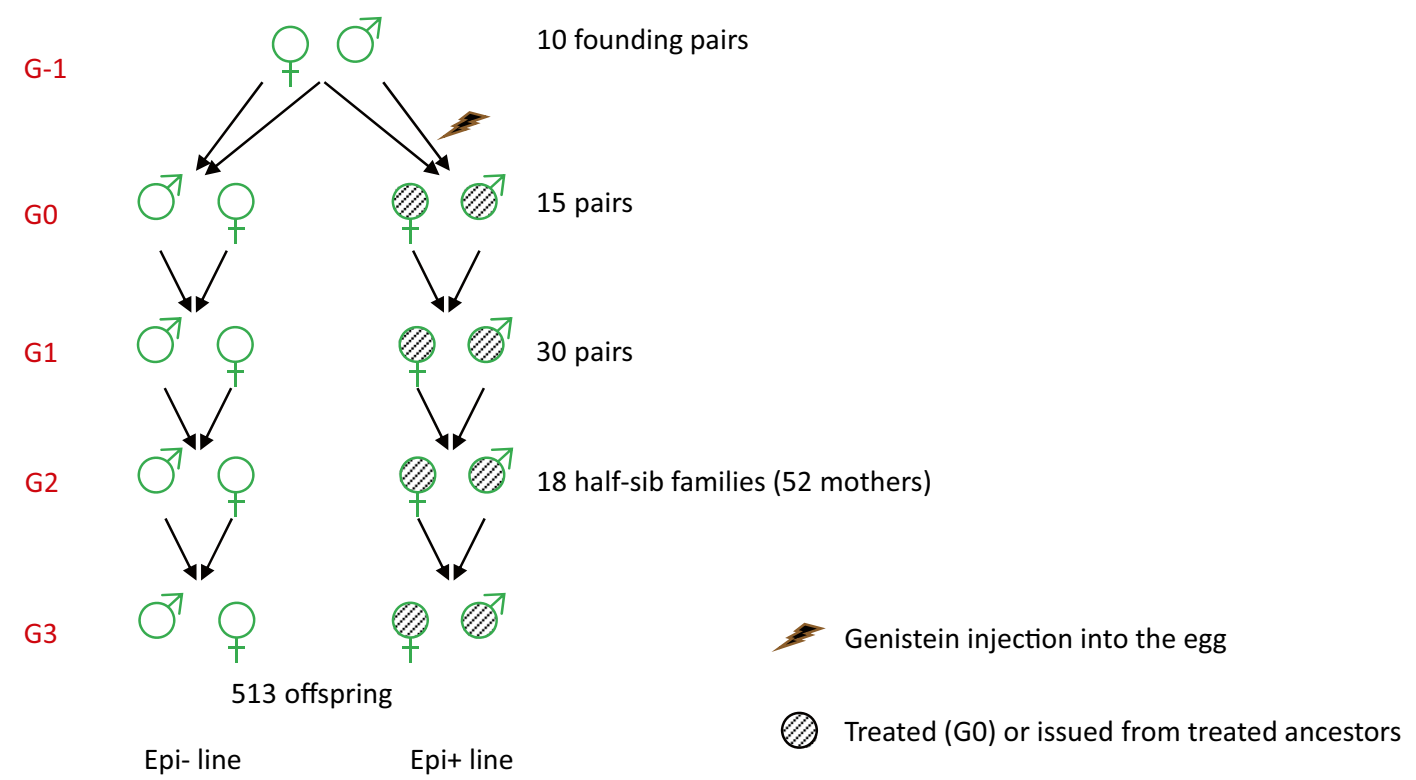

Fig. 1 Experimental design. A single injection of genistein was performed at the onset of egg incubation to produce the first generation (G0). The epilines were then produced through a "mirrored" design (see Additional file 1: Figure S1)

Table 1 Analysis of traits measured on $\mathbf{G} 3$ individuals

\begin{tabular}{lll}
\hline Trait & $\begin{array}{l}\text { Number of indi- } \\
\text { viduals }\end{array}$ & Line effect \\
\hline Body weight at 3 weeks & 513 & - \\
Adult body weight & 332 & - \\
Liver weight & 299 & $=$ \\
Abdominal fat weight & $158^{\mathrm{a}}$ & + \\
Age at first egg & $168^{\mathrm{a}}$ & + \\
Egg number & $168^{\mathrm{a}}$ & - \\
Wingspan & 303 & - \\
Beak temperature & 291 & + \\
Eye temperature & 283 & + \\
Leg temperature & $160^{\mathrm{a}}$ & - \\
Distance & 101 & - \\
Center1 & 101 & $=$ \\
Dist. tread & 96 & $=$ \\
Tl duration & 93 & $=$ \\
G0 methylation level & 16 & $=$ \\
G3 methylation level & 46 &
\end{tabular}

Line effect indicates significant $(+/-)$ or non significant $(=)$ differences between the Epi+ and Epi- lines ( $p<0.05$, see Additional file 2: Table S1). Phenotypes were measured at slaughter ( 27 weeks of age) except for body weight at 3 weeks and behavioral traits (see "Methods"). Methylation levels were measured by LUMA on blood sampled at 23 weeks of age

* $p$-values from the linear mixed model analysis were adjusted with the Benjamini-Hochberg correction

a These traits were measured in females only (since in the original HSR line and in the Epi-and Epi+ lines, abdominal fat is nearly absent in males) age. The number of eggs laid was measured for a subset of females of each line $(n=168)$. The age at first egg and the number of eggs laid during the experimental period (from first egg to 27 weeks of age) were recorded. A subset of individuals $(n=332)$ was reared until 27 weeks of age when birds were sacrificed and body weight, wingspan, liver and abdominal adipose tissue weights were measured.

We estimated the surface temperature of the eye, the beak and the shank using a FLIR B35 infrared digital camera (Wilsonville, USA). A distance of $50 \mathrm{~cm}$ was maintained between the bird and the camera. Images were analyzed with the ThermaCam Pro 2.10 software, with emissivity set to 0.95 . Figure 2 shows the areas of temperature measurement on the quail heads.

Because the selection criterion used in the founder line involved social motivation [25], we investigated whether social behavior was modified in the third-generation individuals. Moreover, we assessed whether initial genistein treatment affected fearfulness since the latter could interfere with social motivation.

\section{Social reinstatement behavior (day 6-7)}

The test procedure used was similar to that described in detail by Mills and Faure [25]. Birds were transferred in groups to a room (A) adjacent to the testing room (B). In room $A$, they were housed in 

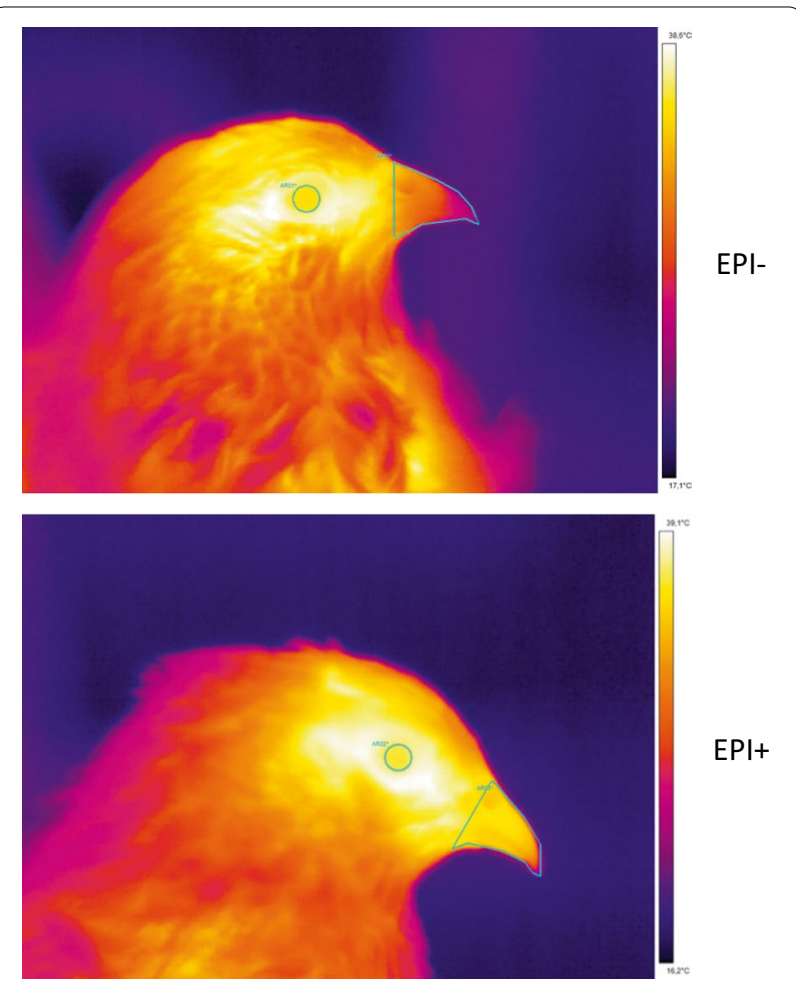

Fig. 2 Thermacam image of two quails. Top panel Epi+ individual. Bottom panel Epi- individual. The areas of temperature measurement are shown

wooden cages that measured $63 \mathrm{~cm} \times 38 \mathrm{~cm} \times 28 \mathrm{~cm}$ (depth $\times$ width $\times$ height), had a wire mesh cover, a bedding of wood shavings, and contained a feed trough and drinker. Feed and water were provided ad libitum. Quails were familiarized with these cages for at least $1 \mathrm{~h}$ before testing. Then, they were tested in room B, a square walled arena $(80 \mathrm{~cm} \times 80 \mathrm{~cm})$ with a central area $(40 \mathrm{~cm} \times 40 \mathrm{~cm})$ and an outlying section $(20 \mathrm{~cm}$ wide along the walls). Social reinstatement behavior was assessed by measuring over a 5 -min period the distance ("dist. tread", arbitrary unit) a single chick ran on a treadmill apparatus to join a group of five conspecifics (see [25] for details).

\section{Tonic immobility (day 11-12)}

Duration of tonic immobility ("TI duration") is a behavioral and physiological response which is modulated by frightening situations and is considered as a measure of the level of fearfulness [29, 30]. Animals were placed on their back in a U-shaped cradle and restrained for $10 \mathrm{~s}$ before the duration of tonic immobility was recorded. If a bird failed to right itself after $3 \mathrm{~min}$, a maximum score of $180 \mathrm{~s}$ was recorded. If tonic immobility was not induced after five attempts, a score of $0 \mathrm{~s}$ was recorded (see [25] for details).

\section{Reaction to social isolation (days 13-14)}

Quails were removed from their brooder cages and transferred in groups of 20 individuals to room A under the same conditions as for the social reinstatement behavior tests. Quail behavior was recorded in room B using a camera placed above the arena and connected to a computer equipped with the Ethovision tracking system $(\mathrm{v}$ XT7.0, Noldus Technology, Wageningen, The Netherlands). The total distance travelled ("distance") and the number of changes from the center to the periphery of the arena ("center1") were recorded over a three-min period.

Traits and performances were analyzed with the "nlme" package of $R$, version 3.0.3 [31, 32] using the linear mixed effects (LME) model with founding single-pair matings (see Additional file 1: Figure S1) as random effects, and line and sex, when necessary, as fixed effects. Body weight was added as a covariate in the model when relevant: fixed effects and covariates were chosen using a stepwise model selection process (stepAIC, from the "MASS" package, $R$ version 3.0.3 [31]). Traits with nonnormal residues were transformed with the BoxCox function [33] and the model was built with the transformed variable (see Additional file 2: Table S1).

\section{LUMA (LUminometric Methylation Assay) analyses}

The global methylation level was measured from whole blood samples of individuals from the G0 ( $\mathrm{n}=8$ for each line) and G3 ( $\mathrm{n}=22 \mathrm{Epi}+$ and $\mathrm{n}=24 \mathrm{Epi}-)$ generations. Genomic DNA was extracted from blood samples using a high-salt extraction method [34]. Methylation analyses were performed using the LUMA assay [35, 36]. Briefly, DNA was digested by EcoRI + HpaII or EcoRI + MspI restriction enzymes (New England Biolabs) and then analyzed using a Q24 Pyromark sequencer (Qiagen). MspI and HpaII have the same recognition site (CCGG), but HpaII is inhibited by the presence of a 5-methylcytosine, while EcoRI (recognition site: GAATTC) is used as an internal control for normalization. Runs were analyzed with PyroMark Q24 1.0.10 software (Qiagen).

The dispensation order for nucleotides was GTGTCACATGTGTG. Methylation levels were calculated from peak heights as $[1-[(\mathrm{HpaII}(\mathrm{G}) / \mathrm{EcoRI} H \mathrm{Hpa}(\mathrm{T})) /$ $(\operatorname{MspI}(\mathrm{G}) /$ EcoRI_Msp(T))] $\times$ 100]. Each pyrosequencing analysis was performed in duplicate.

Statistical analysis (Shapiro-Wilk test of normality and two sample $t$ test) was performed using R version 3.0.3 [31].

\section{Results and discussion}

In order to assess the extent of transgenerational nongenetic inheritance, we measured several traits on third-generation individuals of the Epi+ and Epi- lines. Results are in Table 1. 


\section{Weight traits}

A significant line $\times$ sex interaction $(p=0.012)$ was observed for body weight at 3-weeks of age (Fig. 3): exposure of eggs to genistein increased the weight of males while it decreased the weight of females. Sex-specific effects of environmental programming, including that of the diet fed to dams, have already been observed in G1 individuals in mammals $[37,38]$ and in G2 individuals in birds [39].

The treatment of G0 eggs with genistein significantly altered the body weight of G3 individuals ( $p=0.008$ at 27 weeks of age), Epi- birds being heavier than Epi+ birds. A significant line effect was observed for abdominal adipose tissue, which was reduced in the Epi- line compared with the Epi+ line $(-9.6 \%, p=0.009)$. These results are consistent with a transgenerational effect on quail lipid metabolism through a change in embryonic developmental environment that is triggered by the addition of a methylation modifier into the egg in G0 individuals. Such an effect has been demonstrated in ducks: the diet fed to the dams affects the lipid metabolism of G2 birds through the male line [39].

\section{Reproductive traits}

The line effect on the number of eggs laid was highly significant ( $\mathrm{p}=0.003)$, with the Epi+ line having a lower laying rate than the Epi- line $(-12.7 \%, \mathrm{p}=0.003)$. This difference was mainly due to the age at first egg, since Epi + females started laying eggs more than 8 days after their Epi- counterparts ( $p=0.0007$, see Additional file 2: Table S1). Genistein has been shown to have a direct effect on the reproductive system via different mechanisms $[40,41]$ and in several species (for review see [24]). When added to the diet, genistein tends to increase egg

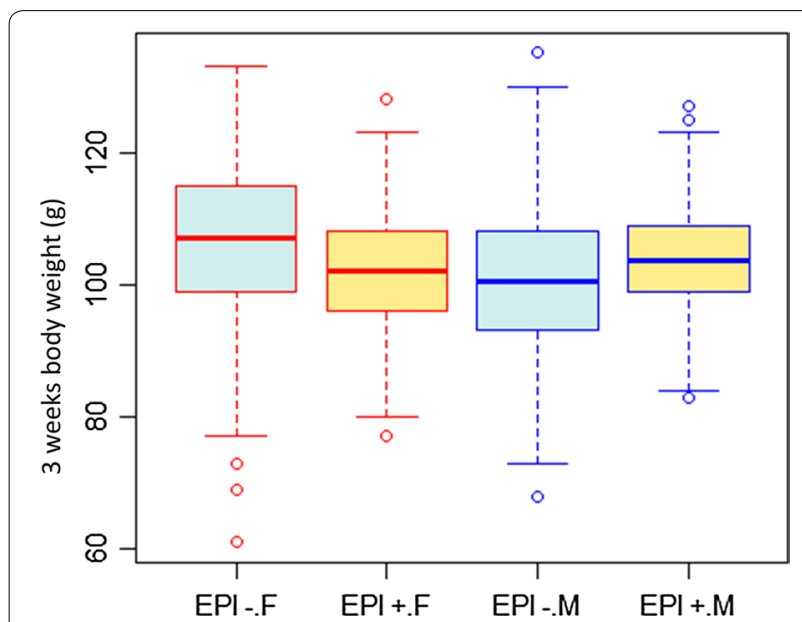

Fig. 3 Boxplot of the body weight at 3 weeks according to line (Epi-/Epi+) and sex. F female, $M$ male production in quail [42], but, in our study, it reduced egg production of G3 females. This is not surprising since the detrimental effect on egg production in G3 is an indirect, transgenerational effect, whereas the known positive effect of dietary genistein on egg production [42] is a direct, primary effect, and the mechanisms involved may differ. At this point, we cannot formulate a strong hypothesis about the putative epigenetic mechanisms involved, in particular because the mode of administration and the generation at which genistein was given differed between both studies. As underlined by Miska and Ferguson-Smith [43], non-DNA sequence-based inheritance may be a way to achieve short-term adaptation. Thus, the effect of a specific environment may trigger a phenotype in one generation (e.g. increased egg production) and an opposite reaction in a later generation (decreased egg production).

\section{Behavioral traits}

None of the behavioral measures were influenced by the sex of the bird. In the isolation test, Epi+ birds walked less $(p=0.012)$ and traveled fewer times from the center to the periphery of the arena $(p=0.026)$ compared with Epi- animals. In this test, walking long distances in the arena, while jumping and calling for other quails, indicates a condition of stress that is characteristic of social isolation [44]. Interestingly, Epi+ birds seemed to be less distressed by the absence of other quails than Epibirds, which have a behavior similar to that of the original HSR parental line. Some previous work in chickens also reported multigenerational changes in behavior when birds experienced unpredictable changes to the lightdark rhythm [45]. This stress resulted in the impaired ability to solve a task based on spatial learning, and was also observed in the offspring [45]. It also induced changes in exploratory behavior in both stressed individuals and their unstressed offspring [46]. Transgenerational differences in exploratory behavior and neophobia have been observed in the F2 generation of mice when the F0 generation received impaired maternal care [47] but, to our knowledge, no previous experiments have mentioned such changes in birds.

In contrast to the isolation test, the Epi+ and Epilines did not differ in their response to fear, as measured through the duration of tonic immobility and social motivation. Emotions are complex responses that reflect different dimensions of the individual $[48,49]$. The response to isolation involves both fear and social responses but also general activity components, with more complex underlying psychophysiological mechanisms than those involved in fear or motivation for social reinstatement alone. This could explain why the response to isolation differed between the Epi+ and Epi- lines, suggesting the 
involvement of epigenetic mechanisms, while the tonic immobility and motivation to join congeners did not. Previous studies have detected seven quantitative trait loci (QTL) related to the response to social isolation in a design including the founder HSR quail line [50]. One of the QTL, on chromosome 19, was also related to age at laying onset, another trait that was modified in Epi+ birds. Further investigations will be needed to investigate whether this locus is specifically affected by epigenetic modifications that could explain these concomitant changes in behavior and in the onset of laying in G3 Epi+ birds.

\section{Temperature-related traits}

Significant line and sex effects were observed for mean eye and beak temperatures, with Epi+ birds displaying higher temperatures than Epi- birds $(\mathrm{p}=0.003$ and $\mathrm{p}=0.0007$, respectively). No differences were observed for the shank temperature but this trait was measured on females only and on a smaller number of birds (Table 1 and see Additional file 2: Table S1). Eye temperature has been proposed as a proxy for body core temperature (see [51]). The handling required for temperature imaging can be considered as an "emotional stressor" and has been shown to affect body temperature in several species, including chickens [52]. Therefore, since Epi+ and Epi- lines differ for behavioral traits related to stress, they may also differ in their physiological responses to temperature-measuring conditions, with a higher level of stress, and, correlatively, higher eye and beak temperatures in Epi+ birds.

\section{Global DNA methylation analyses}

In a first attempt to explain the effect of genistein after several generations without treatment, and to highlight the possible involvement of epigenetic phenomena, we estimated the global level of DNA methylation in the blood of adult birds. DNA methylation is not the only mechanism that may be involved in transgenerational epigenetics [22], but it is the most frequently studied due to technical feasibility. Indeed, DNA methylation has already been shown to be affected in many transgenerational studies in different animal species, including pigs [53]. No significant differences were observed between lines, neither at the G0 nor the G3 generation, and no differences were observed either between G0 and G3 (Table 1 and see Additional file 2: Table S1 and Additional file 3: Figure S2).

These results show that the treatment of ancestors with genistein has no influence on the global methylation level in blood. However, although blood is the most frequently used tissue in methylome studies due to its non-invasive sampling [54], we cannot generalize our results to other tissues in the offspring.

\section{Are offspring phenotypes epigenetically influenced by their ancestors' embryonic environment?}

Several phenotypic traits differ significantly between the two quail lines. However, since the quails analyzed were not completely inbred, non-genetic inheritance of the effect of genistein may not completely explain these differences. In addition, the equal relative genetic contribution of ancestors to the two lines, which was maintained across generations through our "mirrored" single-pair mating design, should have substantially reduced the effect of between-line genetic variability on the differences observed.

Our results are original in the field of environmental transgenerational effects on livestock because several traits were affected, and included both reproductive and behavioral traits. We hypothesize that these differences are neither due to putative chromosomal rearrangements induced by the genistein treatment [55], nor to possible genetic polymorphism diversity between lines, which should be minimal due to the experimental mirrored mating design used.

Global methylation was not affected by genistein treatment, but this does not rule out discrete changes in DNA methylation. Indeed, genistein induces both hyper- and hypo-methylation of genomic regions via mechanisms, notably DNMT1 inhibition, which are not yet completely understood [56-62].

Transgenerational inheritance may be triggered in different ways [63], including miRNA [64], histone modification [65] or DNA methylation [22], and may be involved in human metabolic diseases [66]. Some regions were even shown to evade the genome-wide DNA demethylation, which occurs in the mammalian germline and preimplantation embryos, to induce possible transgenerational effects based on the ancestor's environment [67]. Our study provides evidence of a transgenerational inheritance phenomenon in a bird species, although it is yet unclear which mechanisms may be involved.

\section{Conclusions}

Non-genetic inheritance remains a controversial topic, but our findings agree with previous reports that suggested that some effects induced by environmental stressors can be transmitted across generations. This report adds new evidence to the already long list of putative transgenerational inheritance phenomena, and most interestingly it is the first one in birds. This pilot study on quail should be followed by similar programs using birds of different genetic backgrounds. Moreover, extensive work is required to shed light on the molecular basis, which is likely to be of epigenetic nature, responsible for these transgenerational changes. An important question in animal breeding is to assess to what extent epigenetic 
inheritance may affect the estimation of breeding values in genetic and genomic selection. This question, which is already addressed in plant genomics [4], is receiving more and more attention in animal breeding [3, 68, 69], and this study is a first step towards an answer for poultry.

\section{Additional files}

Additional file 1: Figure S1. Schematic representation of the mirror mating design. As an example, the figure shows the pedigree of two $\mathrm{Epi}+$ and $\mathrm{Epi}$ - birds from the $\mathrm{G} 3$ generation ( $9 \mathrm{E}-$ and $9 \mathrm{E}+$ ) starting from their four founding single-pair matings (SPM) at generation GO. Lines of descent are identified with a different color from each founding SPM. Transmission arrows have solid lines for Epi+ birds and broken ones for Epi-birds. Homologous birds $9 \mathrm{E}+$ and $9 \mathrm{E}-$ have mirror-like, parallel, pedigrees with the same expected genetic contribution from their founders. In this study, matings were designed so that only homologous birds were obtained in the $\mathrm{G} 3$ generation. The $8 \mathrm{E}+$ and $8 \mathrm{E}$ - parents are produced the same way as the $7 \mathrm{E}+$ and $7 \mathrm{E}-$, from 4 different founder pairs.

Additional file 2. Statistical analyses of traits measured on G3 individuals. Table $\mathrm{S} 1$ shows means and statistical analyses for the traits measured on G3 individuals. Lambda parameter of BoxCox transformation is indicated in brackets.

Additional file 3. LUMA results on G3 individuals. Figure $\mathrm{S} 2$ shows mean and standard-deviation of the methylation level (\%). No significant difference was observed between the lines.

\section{Authors' contributions}

FM, MM and FP conceived, designed and coordinated the study. SL, FM and FP drafted the manuscript. DG, SR and FM bred and managed the animals. FM, DG and JLC formulated the experimental treatment. SL, DG, SR, CL, VC, TZ and FP collected phenotypic records and samples and performed experimental analyses. $\mathrm{SL}, \mathrm{CL}, \mathrm{YL}, \mathrm{VC}, \mathrm{TZ}, \mathrm{FM}$ and $\mathrm{FP}$ contributed to the interpretation of the results and to the writing of the manuscript. All authors read and approved the final manuscript.

\section{Author details}

1 GenPhySE, Université de Toulouse, INRA, INPT, ENVT, 31326 Castanet Tolosan, France. ${ }^{2}$ INRA - PEAT, 37380 Nouzilly, France. ${ }^{3}$ UMR INRA PRC, 37380 Nouzilly, France. ${ }^{4}$ CNRS, 37380 Nouzilly, France. ${ }^{5}$ UFR Tours, 37380 Nouzilly, France. ${ }^{6}$ IFCE, 37380 Nouzilly, France. ${ }^{7}$ URA, INRA, 37380 Nouzilly, France. ${ }^{8}$ GABI, INRA, AgroParisTech, Université Paris-Saclay, 78350 Jouy-en-Josas, France.

\section{Acknowledgements}

We are grateful to the entire staff of the PEAT experimental unit for their excellent animal care. We thank Pr. Giancarlo Panzica for advice about genistein treatment, and Helen Munduteguy for English proofreading.

\section{Competing interests}

The authors declare that they have no competing interests.

\section{Availability of data and materials}

The datasets used and/or analysed during the current study are available from the corresponding author on request.

\section{Ethics approval and consent to participate}

Animals were bred at INRA, UE1295 Pôle d'Expérimentation Avicole de Tours, F-37380 Nouzilly in accordance with European Union Guidelines for animal care, following the Council Directives 98/58/EC and 86/609/EEC. Animals were maintained under standard breeding conditions, and subjected to minimal disturbance. The farm is registered with the French Ministry of Agriculture under license number C37-175-1 for animal experimentation. The experiment was conducted under authorization 37-002.

\section{Funding}

This work was funded by the French National Research Agency (ANR; EpiBird grant, ANR-09-GENM-004, http://www.agence-nationale-recherche.fr/).

Received: 16 October 2016 Accepted: 19 January 2017

Published online: 26 January 2017

\section{References}

1. Feil R, Fraga MF. Epigenetics and the environment: emerging patterns and implications. Nat Rev Genet. 2012;13:97-109.

2. Skinner MK. Environmental epigenetics and a unified theory of the molecular aspects of evolution: a neo-lamarckian concept that facilitates neo-darwinian evolution. Genome Biol Evol. 2015;7:1296-302.

3. Goddard ME, Whitelaw E. The use of epigenetic phenomena for the improvement of sheep and cattle. Front Genet. 2014;5:247.

4. Cortijo S, Wardenaar R, Colome-Tatche M, Gilly A, Etcheverry M, Labadie $\mathrm{K}$, et al. Mapping the epigenetic basis of complex traits. Science. 2014:343:1145-8.

5. Eichler EE, Flint J, Gibson G, Kong A, Leal SM, Moore JH, et al. Missing heritability and strategies for finding the underlying causes of complex disease. Nat Rev Genet. 2010;11:446-50.

6. Guay SP, Brisson D, Lamarche B, Gaudet D, Bouchard L. Epipolymorphisms within lipoprotein genes contribute independently to plasma lipid levels in familial hypercholesterolemia. Epigenetics. 2014;9:718-29.

7. Ho DH, Burggren WW. Epigenetics and transgenerational transfer: a physiological perspective. J Exp Biol. 2010;213:3-16.

8. Jablonka E, Raz G. Transgenerational epigenetic inheritance: prevalence, mechanisms, and implications for the study of heredity and evolution. Q Rev Biol. 2009:84:131-76.

9. Skinner MK. Environmental epigenetic transgenerational inheritance and somatic epigenetic mitotic stability. Epigenetics. 2011;6:838-42.

10. Szyf M. Nongenetic inheritance and transgenerational epigenetics. Trends Mol Med. 2015;21:134-44.

11. Greer EL, Maures TJ, Ucar D, Hauswirth AG, Mancini E, Lim JP, et al. Transgenerational epigenetic inheritance of longevity in Caenorhabditis elegans. Nature. 2011;479:365-71.

12. Rechavi $\mathrm{O}$, Minevich $\mathrm{G}$, Hobert $\mathrm{O}$. Transgenerational inheritance of an acquired small RNA-based antiviral response in C. elegans. Cell. 2011;147:1248-56.

13. Remy JJ. Stable inheritance of an acquired behavior in Caenorhabditis elegans. Curr Biol. 2010;20:R877-8.

14. Ashe A, Sapetschnig A, Weick EM, Mitchell J, Bagijn MP, Cording AC, et al. piRNAs can trigger a multigenerational epigenetic memory in the germline of C. elegans. Cell. 2012;150:88-99.

15. Anway MD, Cupp AS, Uzumcu M, Skinner MK. Epigenetic transgenerational actions of endocrine disruptors and male fertility. Science. 2005;308:1466-9.

16. Anway MD, Leathers C, Skinner MK. Endocrine disruptor vinclozolin induced epigenetic transgenerational adult-onset disease. Endocrinology. 2006;147:5515-23.

17. Guerrero-Bosagna C, Settles M, Lucker B, Skinner MK. Epigenetic transgenerational actions of vinclozolin on promoter regions of the sperm epigenome. PLoS One. 2010;5:e13100.

18. Skinner MK, Manikkam M, Haque MM, Zhang B, Savenkova MI. Epigenetic transgenerational inheritance of somatic transcriptomes and epigenetic control regions. Genome Biol. 2012;13:R91.

19. Bhandari RK, vom Saal FS, Tillitt DE. Transgenerational effects from early developmental exposures to bisphenol A or 17alpha-ethinylestradiol in medaka, Oryzias latipes. Sci Rep. 2015;5:9303.

20. Daxinger $L$, Whitelaw E. Understanding transgenerational epigenetic inheritance via the gametes in mammals. Nat Rev Genet. 2012;13:153-62.

21. Burggren WW. Dynamics of epigenetic phenomena: intergenerational and intragenerational phenotype 'washout'. J Exp Biol. 2015;218:80-7.

22. Feng $L$, Chen $X$. Epigenetic regulation of germ cells-remember or forget? Curr Opin Genet Dev. 2015;31:20-7.

23. Minvielle F. The future of Japanese quail for research and production. World Poult Sci J. 2004:60:500-7. 
24. Woclawek-Potocka I, Mannelli C, Boruszewska D, Kowalczyk-Zieba I, Wasniewski T, Skarzynski DJ. Diverse effects of phytoestrogens on the reproductive performance: cow as a model. Int J Endocrinol. 2013;2013:650984.

25. Mills AD, Faure JM. Divergent selection for duration of tonic immobility and social reinstatement behavior in Japanese quail (Coturnix coturnix japonica) chicks. J Comp Psychol. 1991;105:25-38.

26. Viglietti-Panzica C, Mura E, Panzica G. Effects of early embryonic exposure to genistein on male copulatory behavior and vasotocin system of Japanese quail. Horm Behav. 2007;51:355-63.

27. Oppold A, Kress A, Vanden Bussche J, Diogo JB, Kuch U, Oehlmann J, et al. Epigenetic alterations and decreasing insecticide sensitivity of the Asian tiger mosquito Aedes albopictus. Ecotoxicol Environ Saf. 2015;122:45-53.

28. Basu N, Head J, Nam DH, Pilsner JR, Carvan MJ, Chan HM, et al. Effects of methylmercury on epigenetic markers in three model species: mink, chicken and yellow perch. Comp Biochem Physiol C: Toxicol Pharmacol. 2013;157:322-7.

29. Forkman B, Boissy A, Meunier-Salaün MC, Canali E, Jones RB. A critical review of fear tests used on cattle, pigs, sheep, poultry and horses. Physiol Behav. 2007:92:340-74.

30. Jones RB, Mills AD, Faure JM. Genetic and experimental manipulation of fear related behavior in Japanese Quail chicks (Coturnix coturnix japonica). J Comp Psychol. 1991;105:15-24.

31. Team RC. R: A language and environment for statistical computing. Vienna: R Foundation for Statistical Computing; 2014. http://www.Rproject.org/.

32. Pinheiro J, Bates D, DebRoy S, Sarkar D, R CoreTeam. nlme: linear and nonlinear mixed effects models. R package version 3.1-128; 2016. http:// CRAN.R-project.org/package $=$ nlme.

33. Box GEP, Cox DR. An analysis of transformations. J R Stat Soc Series B Stat Methodol. 1964;26:211-52.

34. Roussot O, Feve K, Plisson-Petit F, Pitel F, Faure JM, Beaumont C, et al. AFLP linkage map of the Japanese quail Coturnix japonica. Genet Sel Evol. 2003;35:559-72.

35. Karimi M, Johansson S, Ekstrom TJ. Using LUMA: a luminometric-based assay for global DNA-methylation. Epigenetics. 2006;1:45-8.

36. Karimi M, Johansson S, Stach D, Corcoran M, Grander D, Schalling M, et al. LUMA (LUminometric Methylation Assay) — a high throughput method to the analysis of genomic DNA methylation. Exp Cell Res. 2006;312:1989-95.

37. Gabory A, Attig L, Junien C. Sexual dimorphism in environmental epigenetic programming. Mol Cell Endocrinol. 2009;304:8-18.

38. Gabory A, Attig L, Junien C. Epigenetic mechanisms involved in developmental nutritional programming. World J Diabetes. 2011;2:164-75.

39. Brun JM, Bernadet MD, Cornuez A, Leroux S, Bodin L, Basso B, et al. Influence of grand-mother diet on offspring performances through the male line in Muscovy duck. BMC Genet. 2015;16:145.

40. Nynca A, Sadowska A, Orlowska K, Jablonska M, Ciereszko RE. The effects of phytoestrogen genistein on steroidogenesis and estrogen receptor expression in porcine granulosa cells of large follicles. Folia Biol (Krakow). 2015;63:119-28.

41. Patel S, Zhou C, Rattan S, Flaws JA. Effects of endocrine-disrupting chemicals on the ovary. Biol Reprod. 2015;93:20.

42. Akdemir F, Sahin K. Genistein supplementation to the quail: effects on egg production and egg yolk genistein, daidzein, and lipid peroxidation levels. Poult Sci. 2009;88:2125-31.

43. Miska EA, Ferguson-Smith AC. Transgenerational inheritance: models and mechanisms of non-DNA sequence-based inheritance. Science. 2016;354:59-63.

44. Recoquillay J, Leterrier C, Calandreau L, Bertin A, Pitel F, Gourichon D, et al. Evidence of phenotypic and genetic relationships between sociality, emotional reactivity and production traits in Japanese quail. PLoS One. 2013;8:e82157.

45. Lindqvist C, Janczak AM, Natt D, Baranowska I, Lindqvist N, Wichman A, et al. Transmission of stress-induced learning impairment and associated brain gene expression from parents to offspring in chickens. PLoS One. 2007;2:e364.

46. Natt D, Lindqvist N, Stranneheim H, Lundeberg J, Torjesen PA, Jensen P. Inheritance of acquired behaviour adaptations and brain gene expression in chickens. PLoS One. 2009;4:e6405.
47. Curley JP, Champagne FA, Bateson PP, Keverne EB. Transgenerational effects of impaired maternal care on behaviour of offspring and grandoffspring. Anim Behav. 2008;75:1551-61.

48. Boissy A, Terlouw C, Le Neindre P. Presence of cues from stressed conspecifics increases reactivity to aversive events in cattle: evidence for the existence of alarm substances in urine. Physiol Behav. 1998;63:489-95.

49. Carere C, Maestripieri D. Animal personalities: behavior, physiology, and evolution. Chicago: The University of Chicago Press; 2013.

50. Recoquillay J, Pitel F, Arnould C, Leroux S, Dehais P, Moreno C, et al. A medium density genetic map and QTL for behavioral and production traits in Japanese quail. BMC Genomics. 2015;16:10.

51. Soerensen DD, Pedersen $\sqcup$. Infrared skin temperature measurements for monitoring health in pigs: a review. Acta Vet Scand. 2015;57:5.

52. Edgar JL, Nicol CJ, Pugh CA, Paul ES. Surface temperature changes in response to handling in domestic chickens. Physiol Behav. 2013;119:195-200.

53. Braunschweig M, Jagannathan V, Gutzwiller A, Bee G. Investigations on transgenerational epigenetic response down the male line in F2 pigs. PLoS One. 2012;7:e30583.

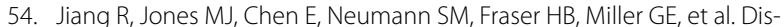
cordance of DNA methylation variance between two accessible human tissues. Sci Rep. 2015;5:8257.

55. Ji W, Hernandez R, Zhang XY, Qu GZ, Frady A, Varela M, et al. DNA demethylation and pericentromeric rearrangements of chromosome 1. Mutat Res. 1997;379:33-41.

56. Day JK, Bauer AM, DesBordes C, Zhuang Y, Kim BE, Newton LG, et al. Genistein alters methylation patterns in mice. J Nutr. 2002;132:2419S-23S.

57. Dolinoy DC, Huang D, Jirtle RL. Maternal nutrient supplementation counteracts bisphenol A-induced DNA hypomethylation in early development. Proc Natl Acad Sci USA. 2007;104:13056-61.

58. Fang MZ, Chen D, Sun Y, Jin Z, Christman JK, Yang CS. Reversal of hypermethylation and reactivation of p16INK4a, RARbeta, and MGMT genes by genistein and other isoflavones from soy. Clin Cancer Res. 2005; 11:7033-41.

59. Vandegehuchte MB, Lemiere F, Vanhaecke L, Vanden Berghe W, Janssen CR. Direct and transgenerational impact on Daphnia magna of chemicals with a known effect on DNA methylation. Comp Biochem Physiol C Toxicol Pharmacol. 2010;151:278-85.

60. Vardi A, Bosviel R, Rabiau N, Adjakly M, Satih S, Dechelotte P, et al. Soy phytoestrogens modify DNA methylation of GSTP1, RASSF1A, EPH2 and BRCA1 promoter in prostate cancer cells. In Vivo. 2010;24:393-400.

61. Xie Q, Bai Q, Zou LY, Zhang QY, Zhou Y, Chang H, et al. Genistein inhibits DNA methylation and increases expression of tumor suppressor genes in human breast cancer cells. Genes Chromosomes Cancer. 2014;53:422-31.

62. Vanhees K, Coort S, Ruijters EJ, Godschalk RW, van Schooten FJ, van Schooten S, Barjesteh van Waalwijk van Doorn-Khosrovani S. Epigenetics: prenatal exposure to genistein leaves a permanent signature on the hematopoietic lineage. FASEB J. 2011;25:797-807.

63. Blake GE, Watson ED. Unravelling the complex mechanisms of transgenerational epigenetic inheritance. Curr Opin Chem Biol. 2016;33:101-7.

64. Rodgers AB, Morgan CP, Leu NA, Bale TL. Transgenerational epigenetic programming via sperm microRNA recapitulates effects of paternal stress. Proc Natl Acad Sci USA. 2015;112:13699-704.

65. Siklenka K, Erkek S, Godmann M, Lambrot R, McGraw S, Lafleur C, et al. Disruption of histone methylation in developing sperm impairs offspring health transgenerationally. Science. 2015;350:aab2006.

66. Stegemann R, Buchner DA. Transgenerational inheritance of metabolic disease. Semin Cell Dev Biol. 2015;43:131-40.

67. Tang WW, Dietmann S, Irie N, Leitch HG, Floros VI, Bradshaw CR, et al. Unique gene regulatory network resets the human germline epigenome for development. Cell. 2015;161:1453-67.

68. van Soom A, Peelman L, Holt WV, Fazeli A. An introduction to epigenetics as the link between genotype and environment: a personal view. Reprod Domest Anim. 2014;49(Suppl 3):2-10.

69. Feeney A, Nilsson E, Skinner MK. Epigenetics and transgenerational inheritance in domesticated farm animals. J Anim Sci Biotechnol. 2014:5:48. 